Article

\title{
Ionic Liquid-Based Non-Aqueous Electrolytes for Nickel/Metal Hydride Batteries
}

\author{
Tiejun Meng ${ }^{1}$, Kwo-Hsiung Young ${ }^{1,2, *}$, Diana F. Wong ${ }^{1}$ and Jean Nei ${ }^{1}$ \\ 1 BASF/Battery Materials-Ovonic, 2983 Waterview Drive, Rochester Hills, MI 48309, USA; \\ tiejun.meng@partners.basf.com (T.M.); diana.f.wong@basf.com (D.F.W.); jean.nei@basf.com (J.N.) \\ 2 Department of Chemical Engineering and Materials Science, Wayne State University, Detroit, MI 48202, USA \\ * Correspondence: kwo.young@basf.com; Tel.: +1-248-293-7000
}

Academic Editor: Andreas Jossen

Received: 9 November 2016; Accepted: 23 January 2017; Published: 6 February 2017

\begin{abstract}
The voltage of an alkaline electrolyte-based battery is often limited by the narrow electrochemical stability window of water $(1.23 \mathrm{~V})$. As an alternative to water, ionic liquid (IL)-based electrolyte has been shown to exhibit excellent proton conducting properties and a wide electrochemical stability window, and can be used in proton conducting batteries. In this study, we used IL/acid mixtures to replace the $30 \mathrm{wt} \% \mathrm{KOH}$ aqueous electrolyte in nickel/metal hydride $(\mathrm{Ni} / \mathrm{MH})$ batteries, and verified the proton conducting character of these mixtures through electrochemical charge/discharge experiments. Dilution of ILs with acetic acid was found to effectively increase proton conductivity. By using $2 \mathrm{M}$ acetic acid in 1-ethyl-3-methylimidazolium acetate, stable charge/discharge characteristics were obtained, including low charge/discharge overpotentials, a discharge voltage plateau at $\sim 1.2 \mathrm{~V}$, a specific capacity of $161.9 \mathrm{mAh} \cdot \mathrm{g}^{-1}$, and a stable cycling performance for an $\mathrm{AB}_{5}$ metal hydride anode with a $(\mathrm{Ni}, \mathrm{Co}, \mathrm{Zn})(\mathrm{OH})_{2}$ cathode.
\end{abstract}

Keywords: ionic liquid (IL); non-aqueous electrolyte; nickel/metal hydride (Ni/MH) batteries

\section{Introduction}

Aqueous-based electrolyte batteries possess apparent advantages over carbonate-based electrolyte Li-ion batteries in terms of safety and cost, despite their relatively lower energy densities. The open circuit voltage of an aqueous electrolyte-based battery is intrinsically limited by the narrow electrochemical stability window of water $(1.23 \mathrm{~V})$, which restricts the selection to electrodes with higher standard potentials (more positive or negative) and presents an obstacle in the improvement of energy density. As an alternative to water and flammable non-aqueous electrolytes (e.g., carbonate, acetonitrile), ionic liquids (ILs) exhibit unique and tunable physicochemical properties, including a wide electrochemical stability window, good ionic conductivity, a wide liquidus range, negligible vapor pressure, good thermal and chemical stability, inflammability, and non-toxicity, all of which have made ILs ideal candidates for many electrochemical applications, such as batteries [1-6], fuel cells [7-12], supercapacitors [13-16] and dye-sensitized solar cells [17-20].

The excellent proton conductivity of ILs has been demonstrated in both fuel cells and proton-conducting batteries. It was reported that diethylmethylammonium trifluoromethanesulfonate ([DEMA][TfO]) exhibits an ionic conductivity of $10 \mathrm{mS} \cdot \mathrm{cm}^{-1}$, and fuel cells using it as the electrolyte show an open circuit voltage of $1.03 \mathrm{~V}[9,10]$. Our recent study on proton-conducting batteries showed a discharge capacity of $3635 \mathrm{mAh} \cdot \mathrm{g}^{-1}$ for a hydrogenated amorphous silicon thin film anode using 1-ethyl-3-methylimidazolium acetate/acetic acid as the electrolyte [21]. For the non-aqueous electrolyte in proton-conducting batteries, a hydrogen-bond network consisting of proton donors and acceptors is required. Long range proton transport occurs in systems with weakly bonded hydrogen networks, where there is rapid hydrogen bond dissociation and formation [22]. Protons move through both 
vehicle and Grotthuss mechanisms [23]. In the latter case, protons hop through the hydrogen-bond network, as illustrated in [21] (Figure 1). It has been demonstrated that the Grotthuss mechanism (structural diffusion) plays an important role in proton transfer, and that the diffusion coefficient of protons subject to the Grotthuss (proton hopping) mechanism is greater than those subject to the vehicle mechanism in the case of imidazole and bis(trifluoromethanesulfonyl)imide acid (HTFSI) mixtures [23]. It has also been reported that proton hopping persists over a wide temperature range (up to $120^{\circ} \mathrm{C}$ ) and results in high proton conductivity and high proton transference numbers in imidazolium bis(trifluoromethylsulfonyl)imide ([Im][TFSI]) with excess imidazole [24]. Depending on the availability of exchangeable protons in the chemical structure, ILs can be categorized into protic ionic liquids (PILs) and aprotic ionic liquids (AILs). PILs are prepared through the neutralization reaction of Brønsted acids and Brønsted bases and have intrinsic exchangeable/active protons. In contrast, all other ILs are categorized as AILs, which do not have exchangeable/active protons. The aforementioned [DEMA][TfO] is a PIL with good proton conductivity. While AILs have generally poor ionic conductivity and are not proton-conductive, acids can be introduced to increase proton conductivity by functioning as proton donors. Therefore, by mixing non-aqueous acids with ILs, a proton-conductive electrolyte with a much larger electrochemical stability window (compared to aqueous electrolyte) can be obtained. Therefore, the energy density of the proton-conducting batteries can be dramatically improved through the utilization of high-potential electrode materials, which are unable to work in aqueous systems.

\section{Cations}

(a)<smiles>CCn1cc[n+](C)c1</smiles>

(c)<smiles>CC[NH+](C)CC</smiles>

(b)<smiles>CCCCn1cc[n+](C)c1</smiles>

(d)<smiles>CC[n+]1cc[nH]c1</smiles>

Anions

(e)

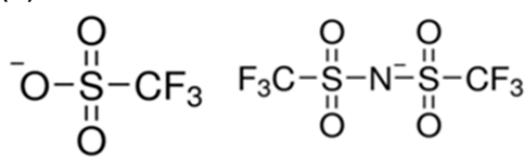

(g)<smiles>CC(=O)[O-]</smiles>

Figure 1. Structures of the cations and anions in the ionic liquids (ILs) used for this study. Cations: (a) 1-ethyl-3-methylimidazolium $\left([\mathrm{EMIM}]^{+}\right)$; (b) 1-butyl-3-methylimidazolium $\left([\mathrm{BMIM}]^{+}\right) ;(\mathbf{c})$ diethylmethylammonium $\left([\mathrm{DEMA}]^{+}\right)$; and (d) 1-ethylimidazolium $\left([\mathrm{EIM}]^{+}\right)$. Anions: (e) trifluoromethanesulfonate $\left([\mathrm{TfO}]^{-}\right) ; \quad(\mathbf{f})$ bis(trifluoromethylsulfonyl)imide ([TFSI $\left.]^{-}\right)$; and (g) acetate $\left([\mathrm{Ac}]^{-}\right)$.

IL-based non-aqueous electrolytes combine a wide electrochemical stability window (typically at least 2-3 times larger than the water-based counterpart) and a high proton conductivity, which are promised to replace water-based electrolytes in proton conducting batteries and further improve the energy density. The nickel/metal hydride $(\mathrm{Ni} / \mathrm{MH})$ battery is one of the most commonly used secondary batteries with a high energy density and the utilization of IL-based non-aqueous electrolytes in $\mathrm{Ni} / \mathrm{MH}$ batteries has not been demonstrated before. In the present work, we developed mixtures of acids and ILs to replace the conventional $30 \mathrm{wt} \% \mathrm{KOH}$ aqueous electrolyte in $\mathrm{Ni} / \mathrm{MH}$ batteries and studied their room temperature electrochemical performances. Unlike the alkaline electrolyte in which the hydrogen transport is in the form of the hydroxide ion $\mathrm{OH}^{-}$, in IL-based electrolyte, the transport of protons is mainly through the Grotthuss mechanism-proton hopping through the hydrogen-bond network that consists of proton donors and acceptors. The cation and anion structures of the ILs in this study are shown in Figure 1 and the physicochemical properties of the eight developed ILs are listed in Table 1. By adding non-aqueous acid such as acetic acid into IL, the ionic conductivity can 
be increased to $\sim 10^{-2} \mathrm{~S} \cdot \mathrm{cm}^{-1}$, which is comparable to that of the carbonate-based electrolyte used in Li-ion batteries and meets the demand for battery electrolyte. The verification of the functionality for the IL-based electrolyte in a Ni/MH battery could enable the use of electrode materials with high voltage and/or capacity which leads to an energy density boost for proton conducting batteries.

Table 1. Physicochemical properties of ILs used in this study. [EMIM][TfO]: 1-ethyl-3-methylimidazolium trifluoromethanesulfonate; [BMIM][TfO]: 1-butyl-3-methylimidazolium trifluoromethanesulfonate; [EMIM][TFSI]: 1-ethyl-3-methylimidazolium bis(trifluoromethylsulfonyl)imide; [BMIM][TFSI]: 1-butyl3-methylimidazolium bis(trifluoromethylsulfonyl)imide; [EMIM][Ac]: 1-ethyl-3-methylimidazolium acetate; [BMIM][Ac]: 1-butyl-3-methylimidazolium acetate; [EIM][TFSI]: 1-ethylimidazolium bis(trifluoromethylsulfonyl)imide; and [DEMA][TfO]: Diethyl\$methylammonium trifluoromethanesulfonate.

\begin{tabular}{|c|c|c|c|c|c|}
\hline IL's Abbreviation & $T_{\text {melt }}\left({ }^{\circ} \mathrm{C}\right)$ & Viscosity (cP) & $\begin{array}{l}\text { Electrochemical } \\
\text { Window (V) }\end{array}$ & $\begin{array}{l}\text { Conductivity at } \\
25^{\circ} \mathrm{C}\left(\mathrm{mS} \cdot \mathrm{cm}^{-1}\right)\end{array}$ & References \\
\hline [EMIM][TfO] & -9 & 45 & 4.1 & $8.6-11$ & [25] \\
\hline [BMIM][TfO] & 16 & 90 & - & 3.7 & [25] \\
\hline [EMIM][TFSI] & $-21 \sim-3$ & $28-34$ & $4.0-4.5$ & $5.7-8.8$ & [25] \\
\hline [BMIM][TFSI] & -4 & 52 & 4.6 & 3.9 & [25] \\
\hline [EMIM][Ac] & $<-20$ & 93 & 3.2 & 2.5 & [26] \\
\hline [BMIM][Ac] & $<-20$ & 554 & 3.1 & 1.1 & [26] \\
\hline [EIM][TFSI] & - & 54 & - & 4 & [8] \\
\hline [DEMA][TfO] & -6 & 19.4 & - & $55 *$ & {$[23,27]$} \\
\hline
\end{tabular}

\section{Experimental Setup}

The electrochemical performance of the non-aqueous IL-based electrolytes was studied by replacing the $30 \mathrm{wt} \% \mathrm{KOH}$ aqueous solution electrolyte in $\mathrm{Ni} / \mathrm{MH}$ batteries with the new electrolyte. The non-aqueous IL-based electrolytes are mixtures of ILs and anhydrous acids. The ILs used in this work include 1-ethyl-3-methylimidazolium trifluoromethanesulfonate ([EMIM][TfO], 99\%, Ionic Liquids Technologies (IoLiTec) Inc., Tuscaloosa, AL, USA), 1-butyl-3-methylimidazolium trifluoromethanesulfonate ([BMIM][TfO], $\geq 95 \%$, Sigma-Aldrich, St. Louis, MO, USA), 1-ethyl-3methylimidazolium bis(trifluoromethylsulfonyl)imide ([EMIM][TFSI], >97\%, IoLiTec GmbH), 1-butyl3-methylimidazolium bis(trifluoromethylsulfonyl)imide ([BMIM][TFSI], $\geq 98 \%$, Aldrich), 1-ethyl-3methylimidazolium acetate ([EMIM][Ac], >95\%, IoLiTec GmbH), 1-butyl-3-methylimidazolium acetate ([BMIM][Ac], $\geq 95 \%$, Aldrich), 1-ethylimidazolium bis(trifluoromethylsulfonyl)imide ([EIM][TFSI], $>97 \%$, IoLiTec $\mathrm{GmbH}$ ), and [DEMA][TfO] (>98\%, IoLiTec GmbH). Prior to use, all ILs were baked at $115^{\circ} \mathrm{C}$ in a vacuum oven for $48 \mathrm{~h}$ to remove residual water. The water content of the IL was then determined to be $<1000$ ppm using a Metrohm 831 KF coulometer (Metrohm, Riverview, FL, USA). Two types of anhydrous acids, glacial acetic acid $\left(\mathrm{CH}_{3} \mathrm{COOH}, 100 \%\right.$, anhydrous for analysis, EMD Millipore, Billerica, MA, USA) and phosphoric acid $\left(\mathrm{H}_{3} \mathrm{PO}_{4}, \geq 99.999 \%\right.$, crystalline, Sigma-Aldrich), were used to create the IL/acid mixtures. The ionic conductivity of the solutions was measured with a conductivity meter (YSI Model 3200, YSI Incorporated, Yellow Spring, OH, USA) at room temperature $\left(25^{\circ} \mathrm{C}\right)$.

The typical negative electrode (anode) for $\mathrm{Ni} / \mathrm{MH}$ batteries uses an $\mathrm{AB}_{5}$ type metal hydride alloy with a composition of $\mathrm{La}_{10.5} \mathrm{Ce}_{4.3} \mathrm{Pr}_{0.5} \mathrm{Nd}_{1.4} \mathrm{Ni}_{60.0} \mathrm{Co}_{12.7} \mathrm{Mn}_{5.9} \mathrm{Al}_{4.7}$ (AB5), which was supplied by Eutectix (Troy, MI, USA). In addition to AB5, two other metal hydride alloys, AR3 and BCC-B08, were also tested. $\mathrm{AR} 3$ is an $\mathrm{MgNi}$-based $\mathrm{AB}$ type $\mathrm{MH}$ alloy with a composition of $\mathrm{Mg}_{52} \mathrm{Ni}_{39} \mathrm{Co}_{3} \mathrm{Mn}_{6}$. The AR3 powder was prepared by melt spinning and mechanical alloying processes using a homebuilt melt spin system and an SC-10 attritor (Union Process, Akron, OH, USA), respectively. BCC-B08 has a bcc crystal structure and a composition of $\mathrm{Ti}_{40} \mathrm{~V}_{30} \mathrm{Cr}_{15} \mathrm{Mn}_{13} \mathrm{Mo}_{2}$ and was prepared by arc melting. The electrochemical properties of AR3 and BCC-B08 have been previously reported [28,29]. The alloy powders were pressed onto a $1.25 \mathrm{~cm}$ (diameter) circular Ni mesh current collectors without any binder or additive. Typically, the active material weight of the negative electrode is $50 \pm 10 \mathrm{mg}$. The positive 
electrode was sintered $\mathrm{Ni}(\mathrm{OH})_{2}$ on a Ni mesh, which was fabricated in-house and is used as a standard positive electrode for our Ni/MH battery research. The positive electrodes were cut into $1.25 \mathrm{~cm}$ (diameter) circular disks and both electrodes were baked at $115^{\circ} \mathrm{C}$ in a vacuum oven for $12 \mathrm{~h}$ before cell assembly. With the aforementioned metal hydride anode, a sintered $\mathrm{Ni}(\mathrm{OH})_{2}$ cathode, a standard non-woven separator $(0.2 \mathrm{~mm}$ thick), and two $1.25 \mathrm{~cm}$ (diameter) nickel rod current collectors, a 1/2" (diameter) Swagelok-type cell (Swagelok, Solon, OH, USA) was assembled in an Ar-filled glove box. Finally, $1 \mathrm{~mL}$ of IL electrolyte was injected into the cell before the cell was sealed for testing.

The electrochemical charge/discharge tests were carried out on an Arbin BT-2143 battery test station (Arbin Instruments, College Station, TX, USA) with a constant charge/discharge current. Cyclic voltammetry (CV) measurements were conducted using a Gamry's Interface 1000 (Gamry Instruments, Warminster, PA, USA) potentiostat/galvanostat in a three-electrode Swagelok cell. The working electrode was an AB5 metal hydride alloy electrode and the counter electrode was a sintered $\mathrm{Ni}(\mathrm{OH})_{2}$ disk. A positive-to-negative capacity ratio of $>10$ was used to minimize the influence from the positive side. A leak-free microminiature reference electrode $(1 \mathrm{~mm}$ diameter, Warner Instruments, Hamden, CT, USA) was inserted through the top port of the Swagelok cell as a reference, which has a standard potential of $0.242 \mathrm{~V}$ versus a standard hydrogen electrode in a $3.4 \mathrm{M}$ $\mathrm{KCl}$ aqueous solution.

\section{Results and Discussion}

\subsection{Ionic Conductivity of Ionic Liquid/Acetic Acid Electrolytes}

Pure ILs exhibit much lower ionic conductivities $(\sigma)$ than conventional aqueous electrolytes. The $[\mathrm{EMIM}]^{+}$cation-based ILs show high conductivity among various types of ILs, typically at $\sim 10 \mathrm{Ms} \cdot \mathrm{cm}^{-1}$ [25], which is comparable to the carbonate-based electrolytes used in Li-ion batteries. This is nearly two orders of magnitude lower than observed with the $30 \mathrm{wt} \% \mathrm{KOH}$ aqueous solutions used in $\mathrm{Ni} / \mathrm{MH}$ batteries.

The relationship between the conductivity and viscosity for dilute aqueous solutions follows the Walden rule:

$$
\Lambda \eta=\mathrm{C} \text { (constant) }
$$

where $\Lambda, \eta$, and $C$ are the molar conductivity, viscosity, and temperature dependent constant, respectively. The Walden rule has been widely used in IL studies to explain the conductivity-viscosity relationship and to estimate the extent of ion association [30-33]. Furthermore, combining the Nernst-Einstein equation for $\Lambda$ and the Stokes-Einstein equation for the diffusion of spherical particles with an effective radius $r, \sigma$ can be expressed as [25]:

$$
\sigma=\frac{z^{2} e^{2} N}{6 V \pi r \eta}
$$

where $z, e, V$, and $N$ denote the valence of the charge carrier, elementary charge, volume, and the number of charge carriers in volume $V$, respectively. It is well known that ILs show higher viscosity, typically $2-3$ orders of magnitude higher than common molecular solvents, due to them containing large cations and/or anions. The viscosities of ILs can increase further with increasing length of the alkyl side chain, due to the longer alkyl side chain increasing the van der Waals interactions [34-36]. According to Equations (1) and (2), high viscosity results in low conductivity, which explains how the [EMIM] ${ }^{+}$-based ILs with lower viscosities (as a result of shorter alkyl side chains) have higher conductivity than their [BMIM] ${ }^{+}$counterparts, as shown in Table 1. It has also been demonstrated by nuclear magnetic resonance (NMR) and molecular dynamics studies that the high viscosity of ILs is due to significant ionic association or aggregation [37-39]. Diluting ILs with solvents can separate the cations and anions in solution and reduce their aggregation, which effectively decreases the viscosity and increases the conductivity. Mixed with molecular solvents, such as acetonitrile and butanone, imidazolium-based ILs show more than an order of magnitude increase in conductivity [40]. In this study, we used anhydrous acetic acid to dilute the ILs to increase 
their conductivities. In addition, acetic acid can also function as a proton donor, which facilitates the proton transport across the electrolyte.

Figure 2 shows the conductivities of the IL/acetic acid mixtures as a function of acetic acid concentration. For all seven IL mixture bases, the conductivity increases with increasing acetic acid concentration in the range of 0-6 M, which is consistent with the discussion above and with previous reports regarding diluted ILs in other solvents [25,40]. The introduction of acetic acid reduces the ion association in ILs and lowers the viscosity. In correlation with the lowered viscosity, the conductivity of the binary system increases. [DEMA][TfO] was the only PIL in this group that showed high conductivity $\left(14.3 \mathrm{mS} \cdot \mathrm{cm}^{-1}\right)$ with $6 \mathrm{M}$ acetic acid $\left(9.0 \mathrm{mS} \cdot \mathrm{cm}^{-1}\right.$ for pure [DEMA][TfO]). The other six AILs consist of two cations, $[\mathrm{EMIM}]^{+}$and $[\mathrm{BMIM}]^{+}$, and three anions, $[\mathrm{TfO}]^{-},[\mathrm{TFSI}]^{-}$and $[\mathrm{Ac}]^{-}$. All three [EMIM] $]^{+}$-based ILs exhibited approximately two times higher conductivities than their [BMIM]+ counterparts in the acetic acid concentration range of $0-6 \mathrm{M}$. [TfO] ${ }^{-}$and [TFSI] ${ }^{-}$-based ILs showed higher conductivities than their $[\mathrm{Ac}]^{-}$counterparts.

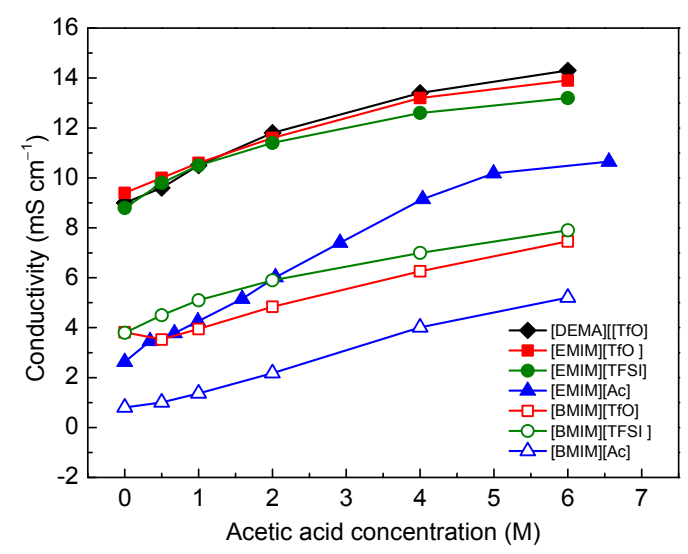

Figure 2. Ionic conductivity as a function of acetic acid concentration in ILs at room temperature.

\subsection{Half-Cell Electrochemical Tests}

In contrast to the electrochemical reactions occurring at the metal hydride anode in aqueous electrolyte [41], where:

$$
\begin{aligned}
\mathrm{M}+\mathrm{H}_{2} \mathrm{O}+\mathrm{e}^{-} & \leftrightarrow \mathrm{MH}_{\mathrm{ads}}+\mathrm{OH}^{-} \\
\mathrm{MH}_{\mathrm{ads}} & \leftrightarrow \mathrm{MH}_{\mathrm{abs}}
\end{aligned}
$$

in non-aqueous proton conducting IL electrolytes, the following reactions occur:

$$
\begin{gathered}
\mathrm{M}+x \mathrm{H}^{+}+x \mathrm{e}^{-} \leftrightarrow \mathrm{MH}_{\mathrm{ads}} \\
\mathrm{MH}_{\mathrm{ads}} \leftrightarrow \mathrm{MH}_{\mathrm{abs}}
\end{gathered}
$$

where $\mathrm{M}$ is the hydrogen storage metal alloy; $\mathrm{MH}$ is metal hydride; the subscripts "ads" and "abs" denote "adsorbed" and "absorbed", respectively; forward and backward arrows represent the charge and discharge processes, respectively. The charge process can be simplified as a two-step process consisting of charge-transfer and hydrogen diffusion. First, protons diffuse in the non-aqueous electrolyte through either the vehicle or Grotthuss mechanisms towards the $\mathrm{MH}$ anode. They are then reduced and adsorbed at the anode-electrolyte interface. The adsorbed hydrogen atoms are further absorbed and diffused into the bulk of the MH. During discharge, protons diffuse toward the anode-electrolyte interface, where they are oxidized and desorbed.

We screened the electrolytes using $1 \mathrm{M}$ acetic acid with eight different ILs in Ni/MH half-cells with an $\mathrm{AB}_{5}$ alloy $(\mathrm{AB} 5)$ anode and an oversized $\mathrm{Ni}(\mathrm{OH})_{2}$ cathode. The electrochemical charge/discharge tests were performed with a constant charge/discharge current of $2 \mathrm{~mA} \cdot \mathrm{g}^{-1}$. The anode was charged to 
$20 \mathrm{mAh} \cdot \mathrm{g}^{-1}$, and the discharge terminated at a cut-off voltage of $0.2 \mathrm{~V}$. Several cycles were required to activate the electrodes and stabilize the charge/discharge processes. Figure 3 shows the charge/discharge curves for eight electrolytes at the 20th cycle. Compared to $30 \mathrm{wt} \% \mathrm{KOH}$ aqueous electrolytes, the conductivities of the IL/acetic acid electrolytes are more than two orders of magnitude lower. It can be observed in Figure 3 that the charge/discharge overpotentials for the IL/acetic acid electrolytes are substantial, which can be attributed to ohmic loss resulting from the high resistance of the non-aqueous electrolytes. Among the eight electrolytes, the acetate-based electrolytes [EMIM][Ac] and [BMIM][Ac] show the smallest charge/discharge overpotentials, with a charge voltage plateau at 1.5-1.7 V and a discharge voltage plateau at 1.4-1.1 V. [EMIM][Ac] has a much flatter discharge voltage plateau than [BMIM][Ac], with a voltage of $1.2 \mathrm{~V}$ at the middle point of the plateau. The other electrolytes, including the $[\mathrm{TfO}]^{-}$- and [TFSI $]^{-}$-based ILs that exhibit high conductivities, showed worse charge/discharge characteristics, in general, than the [Ac] ${ }^{-}$-based ILs. Although the conductivities of the $[\mathrm{Ac}]^{-}$-based ILs are inferior, the shared $[\mathrm{Ac}]^{-}$anion with acetic acid may facilitate Grotthuss diffusion of protons in the electrolyte and charge-transfer at the electrode/electrolyte interface, which results in improved performance compared to other electrolytes.

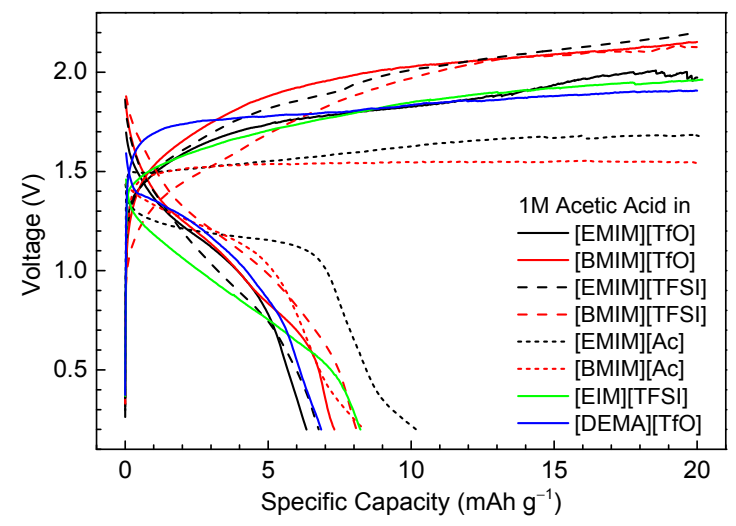

Figure 3. Electrochemical charge/discharge characteristics of nickel/metal hydride (Ni/MH) half-cells with different acetic acid/IL electrolytes at the 20th cycle. The acetic acid concentration was fixed at 1 M. Anode: AB5 MH alloy.

Based on the electrolyte screening results depicted above, a $2 \mathrm{M}$ acetic acid in [EMIM][Ac] was used to conduct the cycle life testing at a higher rate. The cell was charged to a capacity of $40 \mathrm{mAh} \cdot \mathrm{g}^{-1}$ at a current density of $4 \mathrm{~mA} \cdot \mathrm{g}^{-1}$ and discharged at the same current density until a cut-off voltage of $0.7 \mathrm{~V}$ was reached. The evolutions of specific capacity and charge/discharge curves at the 1st, 10th, 20th, 30th, and 100th cycles are shown in Figure 4a,b, respectively.

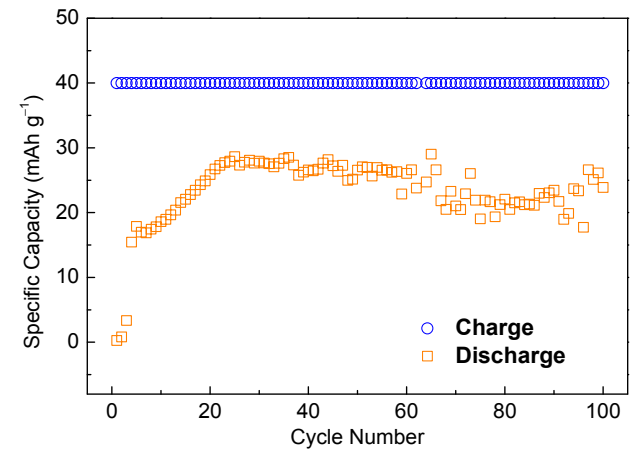

(a)

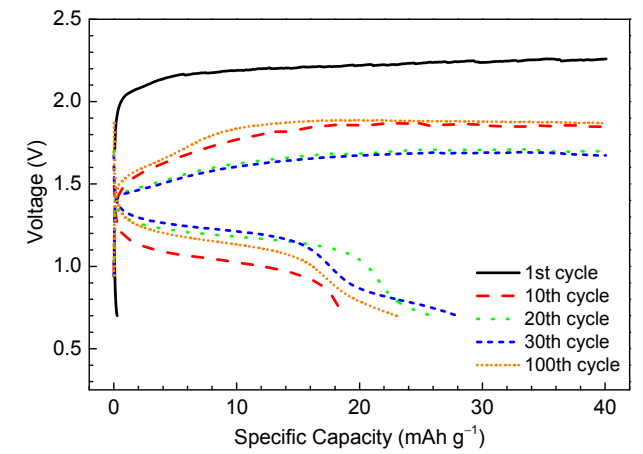

(b)

Figure 4. (a) Specific capacities as a function of cycle number and (b) charge/discharge characteristics at different cycles for a Ni/MH half-cell using $2 \mathrm{M}$ acetic acid/[EMIM][Ac]. Anode: AB5 MH alloy. 
The initial specific capacity was very low, and several cycles were necessary to activate the cell. It is well known that in $\mathrm{KOH}$ electrolyte, many types of $\mathrm{MH}$ anodes need activation process until their capacities reach maximum and charge/discharge overpotentials minimize. Initially, the surface of $\mathrm{MH}$ alloys is covered with highly resistant oxides which hinder the transport of protons. During the activation process, the $\mathrm{MH}$ alloy surfaces experience etching followed by re-oxidation in $\mathrm{KOH}$ which results in a new hydroxide/oxide surface layer (solid electrolyte interphase (SEI) for $\mathrm{Ni} / \mathrm{MH}$ ) embedded with metallic nickel-based nanoclusters. Such a Ni-embedded SEI layer is crucial because it not only catalyzes the electrochemical reactions but also protects the bulk alloy from corrosion. For the IL-based electrolytes, the initial cycles show similar charge/discharge characteristics with increasing specific capacities and decreasing charge/discharge overpotentials. Thus, it is speculated that a surface modification process occurs and further investigation is needed to identify the detailed composition, structure and formation mechanisms of the new SEI. After activation, the capacity increased gradually until a maximum of $28.6 \mathrm{mAh} \cdot \mathrm{g}^{-1}$ was attained at the 25th cycle, after which the capacity slightly degraded to reach $23.9 \mathrm{mAh} \cdot \mathrm{g}^{-1}$ at the 100th cycle. The charge/discharge curves show that there is a very high overpotential for the first charge process, and the discharge capacity is close to zero. At the 10th cycle, the charge/discharge overpotentials were dramatically decreased, with charge and discharge plateaus at $1.8 \mathrm{~V}$ and $1.1 \mathrm{~V}$, respectively. This data demonstrates the lowest charge/discharge overpotentials and highest discharge capacities at the 20th and 30th cycle, with charge and discharge plateaus at $1.6 \mathrm{~V}$ and $1.2 \mathrm{~V}$, respectively. At the 100th cycle, the charge/discharge overpotentials increased slightly, and the discharge capacity decreased as a consequence of cell degradation-typically as a result of $\mathrm{MH}$ anode pulverization/disintegration or corrosion.

Deep charge/discharge tests were carried out with AB5, in addition to AR3 and BCC-B08 alloys, using the optimized electrolyte and the results are shown in Figure 5. The cells were charged to $400 \mathrm{mAh} \cdot \mathrm{g}^{-1}$ at a constant current of $4 \mathrm{~mA} \cdot \mathrm{g}^{-1}$ and discharged at the same current until a cut-off voltage of $0.2 \mathrm{~V}$ was attained.

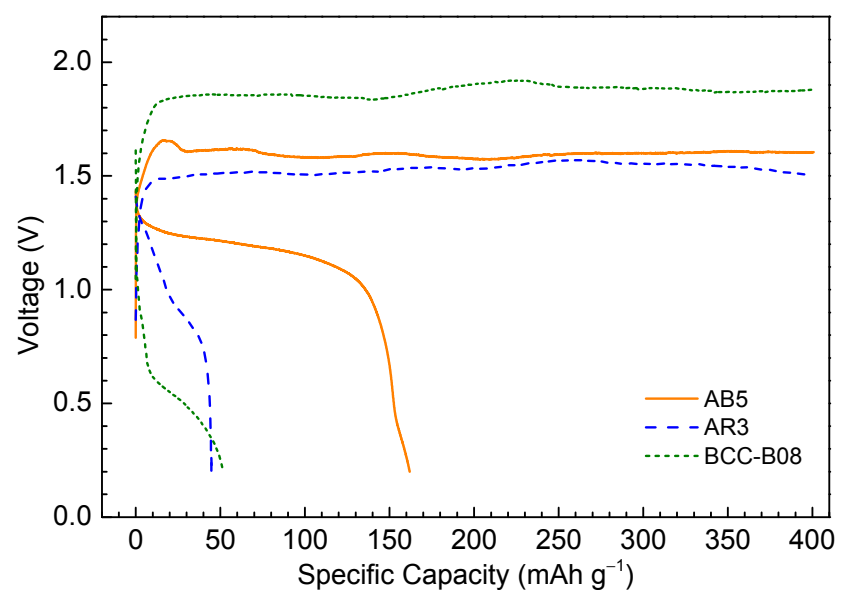

Figure 5. Deep charge/discharge characteristics of $\mathrm{Ni} / \mathrm{MH}$ half-cells using three different metal hydride anodes: AB5, AR3, and BCC-B08. Electrolyte: $2 \mathrm{M}$ acetic acid/[EMIM][Ac].

Among the three metal hydride alloys, AB5 exhibited the best performance, showing the highest capacity at $161.9 \mathrm{mAh} \cdot \mathrm{g}^{-1}$ and stable charge and discharge plateaus at $1.6 \mathrm{~V}$ and $1.2 \mathrm{~V}$, respectively. In comparison, AR3 and BCC-B08 showed much smaller capacities $\left(\sim 50 \mathrm{mAh} \cdot \mathrm{g}^{-1}\right)$, larger charge/discharge overpotentials (except for the charge curve for AR3), and more slanted discharge curves, which may result from poor material stability in the acidic environment or a lack of stable SEI at the alloy surface. Lower specific capacities and higher charge/discharge potentials were obtained for all three $\mathrm{MH}$ alloys in the non-aqueous $2 \mathrm{M}$ acetic acid/[EMIM][Ac] than those in the $30 \mathrm{wt} \% \mathrm{KOH}$ aqueous 
electrolyte. For instance, AB5 exhibited a specific capacity of $\sim 320 \mathrm{mAh} \cdot \mathrm{g}^{-1}$ and charge/discharge voltage plateaus (mid-point) at $\sim 1.45 \mathrm{~V} / 1.25 \mathrm{~V}$ in $30 \mathrm{wt} \% \mathrm{KOH}$. The increase in charge/discharge overpotentials and deficit in specific capacity may result from the following causes. First, the ionic conductivity of $2 \mathrm{M}$ acetic acid/[EMIM][Ac] is around two orders of magnitude lower than that in $30 \mathrm{wt} \% \mathrm{KOH}$, which leads to large charge/discharge overpotentials. Second, a stable SEI may not exist which catalyzes the electrochemical reactions and prevents the corrosion of $\mathrm{MH}$ alloys. Without a stable SEI layer, both slower surface reaction kinetics and more severe corrosions are expected, which lead to increased overpotentials and decreased capacities. Third, there is still a small amount of water left in the electrolyte even though the ILs experienced long-time heating/drying in a vacuum oven. With $>1.5 \mathrm{~V}$ charge voltages, water splitting is expected to occur which leads to the low coulombic efficiency. Also, the sintered $\mathrm{Ni}(\mathrm{OH})_{2}$ might not be stable enough in the weakly acidic environment. It could slowly react with acetic acid and produce water. The search for more stable cathodes used in the non-aqueous system is ongoing.

To improve the proton conducting properties of the IL-based electrolyte, anhydrous phosphoric acid was dissolved into ILs to act as the electrolyte. Phosphoric acid is a solid crystal at room temperature, and its melting temperature is $42{ }^{\circ} \mathrm{C}$. Above its melting point, pure phosphoric acid is a highly viscous liquid with high conductivity $\left(77 \mathrm{mS} \cdot \mathrm{cm}^{-1}\right.$ at $\left.42{ }^{\circ} \mathrm{C}\right)$, which is due to the diffusion of protons [42]. There are more proton donor sites than acceptor sites in phosphoric acid and this amphoteric property makes it an ideal proton conductor [22]. Due to the fact that it occurs as a solid state at room temperature, phosphoric acid exhibits lower solubility in ILs than acetic acid. Three electrolytes, [EMIM][Ac], [EMIM][TfO], and [DEMA][TfO], in $1 \mathrm{M}$ phosphoric acid were prepared and tested in Ni/MH cells with an AB5 alloy electrode. All three electrolytes were highly viscous. The cells were charged to $40 \mathrm{mAh} \cdot \mathrm{g}^{-1}$ at a current of $4 \mathrm{~mA} / \mathrm{g}$ and discharged at the same current until a cut-off voltage of $0.2 \mathrm{~V}$. As shown in Figure 6, all three $1 \mathrm{M}$ phosphoric acid/IL electrolytes AB5 anodes exhibit low specific capacities and large charge/discharge overpotentials. The mid-point charge/discharge voltages are $>1.8 \mathrm{~V} /<1 \mathrm{~V}$, compared to $1.6 \mathrm{~V} / 1.2 \mathrm{~V}$ for $2 \mathrm{M}$ acetic acid/[EMIM][Ac]. The highest specific capacity obtained is from $1 \mathrm{M}$ phosphoric acid/[EMIM][TfO], $\sim 21 \mathrm{mAh} \cdot \mathrm{g}^{-1}$, compared to $28 \mathrm{mAh} \cdot \mathrm{g}^{-1}$ for $2 \mathrm{M}$ acetic acid/[EMIM][Ac]. The phosphoric acid/IL electrolytes exhibit higher viscosities and lower ionic conductivities than those in the acetic acid/IL electrolytes. In addition, both the $\mathrm{MH}$ anode and $\mathrm{Ni}(\mathrm{OH})_{2}$ cathode are not stable in the phosphoric acid/IL electrolytes and the battery cells exhibit short cycle life ( $<30$ cycles). All these caused the poor performances for phosphoric acid/IL electrolytes.

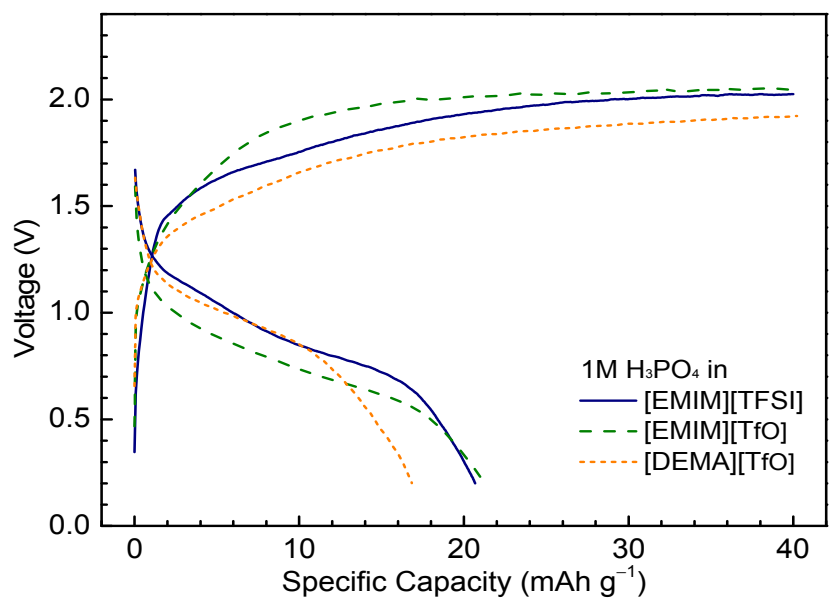

Figure 6. Electrochemical charge/discharge characteristics of $\mathrm{Ni} / \mathrm{MH}$ half-cells using $1 \mathrm{M}$ phosphoric acid with [EMIM][TFSI], [EMIM][TfO], and [DEMA][TfO]. Anode: AB5 MH alloy. 


\subsection{Cyclic Voltammetry}

$\mathrm{CV}$ measurements were performed on a three-electrode Swagelok cell with $2 \mathrm{M}$ acetic acid/[EMIM][Ac] electrolyte and the candidate that showed the best electrochemical performance in this study. The working electrode is an AB5 alloy electrode that is activated with 10 charge/discharge cycles. The counter electrode was sintered $\mathrm{Ni}(\mathrm{OH})_{2}$, and a leak-free microminiature reference electrode $(\mathrm{Ag} / \mathrm{AgCl}, 0.242 \mathrm{~V}$ versus the standard hydrogen electrode) was inserted through the top port of the Swagelok cell to act as a reference. A three-electrode cell with the $30 \mathrm{wt} \% \mathrm{KOH}$ aqueous electrolyte and an $\mathrm{Hg} / \mathrm{HgO}$ reference electrode was used for comparison. The cyclic voltammograms for $2 \mathrm{M}$ acetic acid/[EMIM][Ac] and $30 \mathrm{wt} \% \mathrm{KOH}$ are shown in Figure 7a,b, respectively. With $2 \mathrm{M}$ acetic acid/[EMIM][Ac], the anodic and cathodic peaks are clearly presented. The anodic peak originates from the oxidation and desorption of absorbed hydrogen atoms at the anode-electrolyte interface, while the cathodic peak results from the reduction and adsorption of protons at the interface. The anodic peak is situated near $-0.4 \mathrm{~V}$ versus the reference electrode with a scan rate of $50 \mathrm{mV} \cdot \mathrm{s}^{-1}$. As the scan rate increases, the anodic peak current increases and the peak potential shifts slightly in the positive direction. A full cathodic peak was observed with a center near $-1.0 \mathrm{~V}$ versus the reference electrode. There is about a $0.6 \mathrm{~V}$ voltage gap between the hydrogen cathodic peak and the edge of the reduction of the electrolyte. Theoretically, such a voltage gap is enough to guarantee a high coulombic efficiency. However, in the cycle test, as shown in Figure 4, the coulombic efficiency is less than $70 \%$, which is attributed to the splitting of residual water in the electrolyte during charge, as discussed in Section 3.2. Approaches to remove water completely from ILs and more stable cathodes compatible with the weakly acidic environment are under current investigation. With the $30 \mathrm{wt} \%$ $\mathrm{KOH}$ aqueous electrolyte, the $\mathrm{CV}$ curves exhibit wrinkle-like features starting at approximately $-0.9 \mathrm{~V}$ versus $\mathrm{Hg} / \mathrm{HgO}$, and no obvious cathodic peaks are observed. In fact, the cathodic peak is so close to the hydrogen evolution threshold that it overlaps with the hydrogen evolution edge and cannot be differentiated, which is consistent with previous reports [41,43-45]. The acetic acid/[EMIM][Ac] electrolyte prevails over the $30 \mathrm{wt} \% \mathrm{KOH}$ electrolyte in terms of the electrochemical stability window, which means that the use of redox couples with higher potentials is a possibility. A non-aqueous environment also enables the study of electrode materials that are not stable in aqueous solutions, with the goal of improving capacities. As a consequence, a marked increase in the energy density is expected for proton conducting batteries.

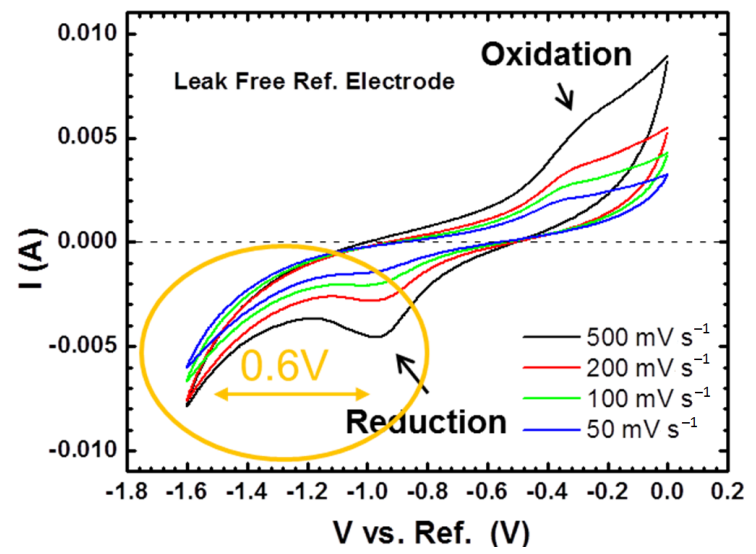

(a)

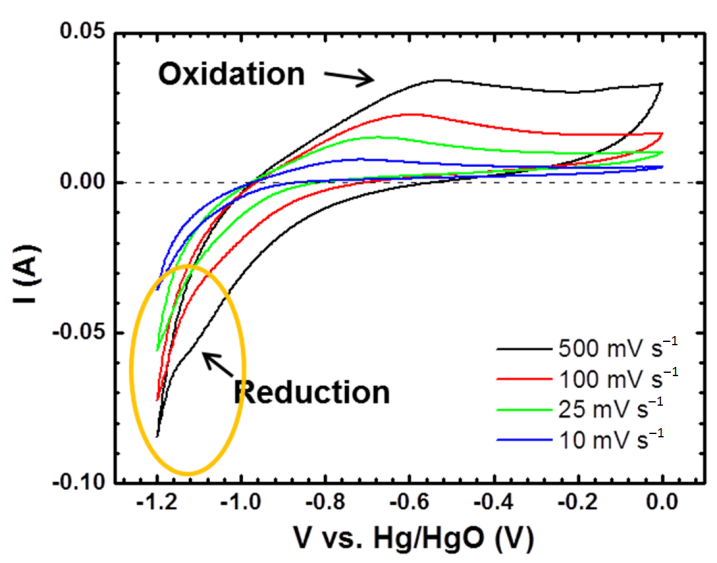

(b)

Figure 7. Cyclic voltammograms of $\mathrm{Ni} / \mathrm{MH}$ half-cells using (a) $2 \mathrm{M}$ acetic acid in [EMIM][Ac] as an electrolyte and (b) the $30 \mathrm{wt} \% \mathrm{KOH}$ aqueous electrolyte. 


\section{Conclusions}

$\mathrm{IL} /$ acid mixtures were applied in $\mathrm{Ni} / \mathrm{MH}$ batteries to replace the $30 \mathrm{wt} \% \mathrm{KOH}$ aqueous electrolyte, and their proton conducting character was verified through electrochemical charge/discharge tests. Pure ILs are viscous and, when diluted with acetic acid, this viscosity decreases and conductivity increases. [DEMA][TfO] with $6 \mathrm{M}$ acetic acid showed a conductivity of $14.3 \mathrm{mS} \cdot \mathrm{cm}^{-1}$, compared to $9.0 \mathrm{mS} \cdot \mathrm{cm}^{-1}$ for pure [DEMA][TfO]. In addition, the introduction of acetic acid introduces proton donors, which are crucial for the diffusion of protons. Screening eight different ILs, a mixture of acetic acid/[EMIM][Ac] exhibited the best electrochemical performance with a long cycle life, low charge/discharge overpotentials, and a stable discharge voltage plateau at $\sim 1.2 \mathrm{~V}$. A specific capacity of $161.9 \mathrm{mAh} \cdot \mathrm{g}^{-1}$ was obtained with an AB5 anode in a $2 \mathrm{M}$ acetic acid/[EMIM][Ac] electrolyte, which exhibited a voltage difference of approximately $0.6 \mathrm{~V}$ between the cathodic peak and the electrolyte reduction edge, based on CV measurements. An extended electrochemical stability window enables the use of redox couples with higher potentials than those currently in use with aqueous electrolyte, which is expected to boost the energy density of proton conducting batteries.

Acknowledgments: This work is financially supported by the U.S. Department of Energy's Advanced Research Project Agency-Energy (ARPA-E) under the Robust Affordable Next Generation EV-storage (RANGE) Program (DE-AR0000386).

Author Contributions: Tiejun Meng and Kwo-Hsiung Young designed the experiments and analyzed the results. Diana F. Wong and Jean Nei assisted in data analysis and manuscript preparation.

Conflicts of Interest: The authors declare no conflict of interest.

\section{Abbreviations}

IL

[DEMA][TfO]

[Im][TFSI]

PIL

AIL

$\mathrm{Ni} / \mathrm{MH}$

[EMIM][TfO]

[BMIM][TfO]

[EMIM][TFSI]

[BMIM][TFSI]

[EMIM][Ac]

[BMIM][Ac]

[EIM][TFSI]

$\mathrm{CV}$

$\sigma$

$\Lambda$

$\eta$

C

$r$

$z$

e

V

N

NMR

$M$

$\mathrm{MH}$

ads

abs

SEI
Ionic liquid

Diethylmethylammonium trifluoromethanesulfonate

Imidazolium bis(trifluoromethylsulfonyl)imide

Protic ionic liquid

Aprotic ionic liquid

Nickel/metal hydride

1-ethyl-3-methylimidazolium trifluoromethanesulfonate

1-butyl-3-methylimidazolium trifluoromethanesulfonate

1-ethyl-3-methylimidazolium bis(trifluoromethylsulfonyl)imide

1-butyl-3-methylimidazolium bis(trifluoromethylsulfonyl)imide

1-ethyl-3-methylimidazolium acetate

1-butyl-3-methylimidazolium acetate

1-ethylimidazolium bis(trifluoromethylsulfonyl)imide

Cyclic voltammetry

Conductivity

Molar conductivity

Viscosity

Temperature dependent constant

Effective radius of spherical particles

Valence of the charge carrier

Elementary charge

Number of charge carriers

Volume

Nuclear magnetic resonance

Hydrogen storage metal alloy

Metal hydride

Adsorbed

Absorbed

Solid electrolyte interface 


\section{References}

1. Yamamoto, T.; Nohira, T.; Hagiwara, R.; Fukunaga, A.; Sakai, S.; Nitta, K.; Inazawa, S. Charge-discharge behavior of tin negative electrode for a sodium secondary battery using intermediate temperature ionic liquid sodium bis(fluorosulfonyl)amide-potassium bis(fluorosulfonyl)amide. J. Power Sources 2012, 217, 479-484. [CrossRef]

2. Nohira, T.; Ishibashi, T.; Hagiwara, R. Properties of an intermediate temperature ionic liquid NaTFSA-CsTFSA and charge-discharge properties of $\mathrm{NaCrO}_{2}$ positive electrode at $423 \mathrm{~K}$ for a sodium secondary battery. J. Power Sources 2012, 205, 506-509. [CrossRef]

3. Khoo, T.; Somers, A.; Torriero, A.A.J.; MacFarlane, D.R.; Howlett, P.C.; Forsyth, M. Discharge behaviour and interfacial properties of a magnesium battery incorporating trihexyl(tetradecyl)phosphonium based ionic liquid electrolytes. Electrochim. Acta 2013, 87, 701-708. [CrossRef]

4. Kakibe, T.; Hishii, J.Y.; Yoshimoto, N.; Egashira, M.; Morita, M. Binary ionic liquid electrolytes containing organo-magnesium complex for rechargeable magnesium batteries. J. Power Sources 2012, 203, $195-200$. [CrossRef]

5. Simons, T.J.; Howlett, P.C.; Torriero, A.A.J.; MacFarlane, D.R.; Forsyth, M. Electrochemical, transport, and spectroscopic properties of 1-ethyl-3-methylimidazolium ionic liquid electrolytes containing zinc dicyanamide. J. Phys. Chem. C 2013, 117, 2662-2669. [CrossRef]

6. Simons, T.J.; Torriero, A.A.J.; Howlett, P.C.; MacFarlane, D.R.; Forsyth, M. High current density, efficient cycling of $\mathrm{Zn}^{2+}$ in 1-ethyl-3-methylimidazolium dicyanamide ionic liquid: The effect of $\mathrm{Zn}^{2+}$ salt and water concentration. Electrochem. Commun. 2012, 18, 119-122. [CrossRef]

7. Lee, S.-Y.; Ogawa, A.; Kanno, M.; Nakamoto, H.; Yasuda, T.; Watanabe, M. Nonhumidified intermediate temperature fuel cells using protic ionic liquids. J. Am. Chem. Soc. 2010, 132, 9764-9773. [CrossRef] [PubMed]

8. Susan, M.A.B.H.; Noda, A.; Mitsushima, S.; Watanabe, M. Brønsted acid-base ionic liquids and their use as new materials for anhydrous proton conductors. Chem. Commun. 2003, 8, 938-939. [CrossRef]

9. Nakamoto, H.; Watanabe, M. Brønsted acid-base ionic liquids for fuel cell electrolytes. Chem. Commun. 2007, 24, 2539-2541. [CrossRef] [PubMed]

10. Yasuda, T.; Nakamura, S.-I.; Honda, Y.; Kinugawa, K.; Lee, S.-Y.; Watanabe, M. Effects of polymer structure on properties of sulfonated polyimide/protic ionic liquid composite membranes for nonhumidified fuel cell applications. ACS Appl. Mater. Interfaces 2012, 4, 1783-1790. [CrossRef] [PubMed]

11. Matsumoto, H.; Sakaebe, H.; Tatsumi, K.; Kikuta, M.; Ishiko, E.; Kono, M. Fast cycling of Li/LiCoO 2 cell with low-viscosity ionic liquids based on bis(fluorosulfonyl)imide [FSI] ${ }^{-}$. J. Power Sources 2006, 160, 1308-1313. [CrossRef]

12. Ishikawa, M.; Sugimoto, T.; Kikuta, M.; Ishiko, E.; Kono, M. Pure ionic liquid electrolytes compatible with a graphitized carbon negative electrode in rechargeable lithium-ion batteries. J. Power Sources 2006, 162, 658-662. [CrossRef]

13. Tsai, W.Y.; Lin, R.Y.; Murali, S.; Zhang, L.L.; McDonough, J.K.; Ruoff, R.S.; Taberna, P.L.; Gogotsi, Y.; Simon, P. Outstanding performance of activated graphene based supercapacitors in ionic liquid electrolyte from -50 to $80{ }^{\circ} \mathrm{C}$. Nano Energy 2013, 2, 403-411. [CrossRef]

14. Lin, R.Y.; Taberna, P.L.; Fantini, S.; Presser, V.; Perez, C.R.; Malbosc, F.; Rupesinghe, N.L.; Teo, K.B.K.; Gogotsi, Y.; Simon, P. Capacitive energy storage from -50 to $100{ }^{\circ} \mathrm{C}$ using an ionic liquid electrolyte. J. Phys. Chem. Lett. 2011, 2, 2396-2401. [CrossRef]

15. Lin, Z.; Taberna, P.-L.; Simon, P. Graphene-based supercapacitors using eutectic ionic liquid mixture electrolyte. Electrochim. Acta 2016, 206, 446-451. [CrossRef]

16. Balducci, A.; Bardi, U.; Caporali, S.; Mastragostino, M.; Soavi, F. Ionic liquids for hybrid supercapacitors. Electrochem. Commun. 2004, 6, 566-570. [CrossRef]

17. Bai, Y.; Cao, Y.; Zhang, J.; Wang, M.; Li, R.; Wang, P.; Zakeeruddin, S.M.; Gratzel, M. High-performance dye-sensitized solar cells based on solvent-free electrolytes produced from eutectic melts. Nat. Mater. 2008, 7, 626-630. [CrossRef] [PubMed]

18. Bai, Y.; Zhang, J.; Wang, Y.; Zhang, M.; Wang, P. Lithium-modulated conduction band edge shifts and charge-transfer dynamics in dye-sensitized solar cells based on a dicyanamide ionic liquid. Langmuir 2011, 27, 4749-4755. [CrossRef] [PubMed] 
19. Zhang, M.; Zhang, J.; Bai, Y.; Wang, Y.; Su, M.; Wang, P. Anion-correlated conduction band edge shifts and charge transfer kinetics in dye-sensitized solar cells with ionic liquid electrolytes. Phys. Chem. Chem. Phys. 2011, 13, 3788-3794. [CrossRef] [PubMed]

20. Kawano, R.; Watanabe, M. Equilibrium potentials and charge transport of an $\mathrm{I}^{-} / \mathrm{I}_{3}{ }^{-}$redox couple in an ionic liquid. Chem. Commun. 2003, 3, 330-331. [CrossRef]

21. Meng, T.; Young, K.; Beglau, D.; Yan, S.; Zeng, P.; Cheng, M.M.-C. Hydrogenated amorphous silicon thin film anode for proton conducting batteries. J. Power Sources 2016, 302, 31-38. [CrossRef]

22. Kreuer, K.-D.; Paddison, S.J.; Spohr, E.; Schuster, M. Transport in proton conductors for fuel-cell applications: Simulations, elementary reactions, and phenomenology. Chem. Rev. 2004, 104, 4637-4678. [CrossRef] [PubMed]

23. Yasuda, T.; Watanabe, M. Protic ionic liquids: Fuel cell applications. MRS Bull. 2013, 38, 560-566. [CrossRef]

24. Hoarfrost, M.L.; Tyagi, M.; Segalman, R.A.; Reimer, J.A. Proton hopping and long-range transport in the protic ionic liquid [Im][TFSI], probed by pulsed-field gradient NMR and quasi-elastic neutron scattering. J. Phys. Chem. B 2012, 116, 8201-8209. [CrossRef] [PubMed]

25. Galinski, M.; Lewandowski, A.; Stepniak, I. Ionic liquids as electrolytes. Electrochim. Acta 2006, 51, 5567-5580. [CrossRef]

26. ILCO Chemikalien GmbH. Ionic Liquid. Available online: http://www.ilco-chemie.de/downloads/Ionic\% 20Liquid.pdf (accessed on 24 October 2016).

27. Walsh, D.A.; Ejigu, A.; Smith, J.; Licence, P. Kinetics and mechanism of oxygen reduction in a protic ionic liquid. Phys. Chem. Chem. Phys. 2013, 15, 7548-7554. [CrossRef] [PubMed]

28. Nei, J.; Young, K.; Rotarov, D. Studies on MgNi-based metal hydride electrode with aqueous electrolytes composed of various hydroxides. Batteries 2016, 2, 27. [CrossRef]

29. Liao, X.; Yin, Z.; Young, K.; Nei, J. Studies in molybdenum/manganese content in the dual body-centered-cubic phases metal hydride alloys. Int. J. Hydrog. Energy 2016, 41, 15277-15286. [CrossRef]

30. $\mathrm{Xu}, \mathrm{W}$; Angell, C.A. Solvent-free electrolytes with aqueous solution-like conductivities. Science 2003, 302, 422-425. [CrossRef] [PubMed]

31. Yoshizawa, M.; Xu, W.; Angell, C.A. Ionic liquids by proton transfer: Vapor pressure, conductivity, and the relevance of $\Delta \mathrm{p} K_{\mathrm{a}}$ from aqueous solutions. J. Am. Chem. Soc. 2003, 50, 15411-15419. [CrossRef] [PubMed]

32. Fraser, K.J.; Izgorodina, E.I.; Forsyth, M.; Scott, J.L.; Macfarlane, D.R. Liquids intermediate between "molecular" and "ionic" liquids: Liquid ion pairs? Chem. Commun. 2007, 37, 3817-3819. [CrossRef]

33. MacFarlane, D.R.; Forsyth, M.; Izgorodina, E.I.; Abbott, A.P.; Annat, G.; Fraser, K. On the concept of ionicity in ionic liquids. Phys. Chem. Chem. Phys. 2009, 11, 4962-4967. [CrossRef] [PubMed]

34. Bonhote, P.; Dias, A.; Papageorgiou, N.; Kalyanasundaram, K.; Gratzel, M. Hydrophobic, highly conductive ambient-temperature molten salts. Inorg. Chem. 1996, 35, 1168-1178. [CrossRef] [PubMed]

35. Yu, G.; Zhao, D.; Wen, L.; Yang, S.; Chen, X. Viscosity of ionic liquids: Database, observation, and quantitative structure-property relationship analysis. AIChE J. 2012, 58, 2885-2899. [CrossRef]

36. Rocha, M.A.A.; Neves, C.M.S.S.; Freire, M.G.; Russina, O.; Triolo, A.; Coutinho, J.A.P.; Santos, L.M.N.B.F. Alkylimidazolium based ionic liquids: Impact of cation symmetry on their nanoscale structural organization. J. Phys. Chem. B 2013, 117, 10889-10897. [CrossRef] [PubMed]

37. Wang, Y.T.; Voth, G.A. Unique spatial heterogeneity in ionic liquids. J. Am. Chem. Soc. 2005, 127, 12192-12193. [CrossRef] [PubMed]

38. Paul, A.; Kumar, P.; Samanta, A. On the optical properties of the imidazolium ionic liquids. J. Phys. Chem. B 2005, 109, 9148-9153. [CrossRef] [PubMed]

39. Lopes, J.N.A.C.; Padua, A.A.H. Nanostructural organization in ionic liquids. J. Phys. Chem. B 2006, 110, 3330-3335. [CrossRef] [PubMed]

40. Zhu, A.; Wang, J.; Han, L.; Fan, M. Measurements and correlation of viscosities and conductivities for the mixtures of imidazolium ionic liquids with molecular solutes. Chem. Eng. J. 2009, 147, 27-35. [CrossRef]

41. Yuan, X.; Xu, N. Determination of hydrogen diffusion coefficient in metal hydride electrode by cyclic voltammetry. J. Alloy. Compd. 2001, 316, 113-117. [CrossRef]

42. Dippel, T.; Kreuer, K.D.; Lassegues, J.C.; Rodriguez, D. Proton conductivity in fused phosphoric acid; A ${ }^{1} \mathrm{H} /{ }^{31}$ P PFG-NMR and QNS study. Solid State Ion. 1993, 61, 41-46. [CrossRef] 
43. Tliha, M.; Mathlouthi, H.; Khaldi, C.; Lamloumi, J.; Percheron-guegan, A. Electrochemical properties of the $\mathrm{LaNi}_{3.55} \mathrm{Mn}_{0.4} \mathrm{Al}_{0.3} \mathrm{Co}_{0.4} \mathrm{Fe}_{0.35}$ hydrogen storage alloy. J. Power Sources 2006, 160, 1391-1394. [CrossRef]

44. Geng, M.; Feng, F.; Gamboa, S.A.; Sebastian, P.J.; Matchett, A.J.; Northwood, D.O. Electrocatalytic characteristics of the metal hydride electrode for advanced Ni/MH batteries. J. Power Sources 2001, 96, 90-93. [CrossRef]

45. Li, X.; Dong, H.; Zhang, A.; Wei, Y. Electrochemical impedance and cyclic voltammetry characterization of a metal hydride electrode in alkaline electrolytes. J. Alloy. Compd. 2006, 426, 93-96. [CrossRef] 